\title{
Agonists of the G protein-coupled receptor 109A-mediated pathway promote antilipolysis by reducing serine residue 563 phosphorylation of hormone-sensitive lipase in bovine adipose tissue explants
}

\author{
Á. Kenéz, ${ }^{*}$ L. Locher,† J. Rehage,† S. Dänicke,‡ and K. Huber*1 \\ *Department of Physiology, and \\ †Clinic for Cattle, University of Veterinary Medicine Hannover, Foundation, Hannover D-30173, Germany \\ łInstitute of Animal Nutrition, Friedrich-Loeffler-Institute, Federal Research Institute for Animal Health, Braunschweig D-38116, Germany
}

\begin{abstract}
A balanced lipolytic regulation in adipose tissues based on fine-tuning of prolipolytic and antilipolytic pathways is of vital importance to maintain the metabolic health in dairy cows. Antilipolytic pathways, such as the G protein-coupled receptor 109A (GPR109A)mediated pathway and the insulin signaling pathway in bovine adipose tissues may be involved in prohibiting excessive lipomobilization by reducing triglycerol hydrolysis. This study aimed to evaluate the in vitro antilipolytic potential of the mentioned pathways in bovine adipose tissue explants. Therefore, subcutaneous and retroperitoneal adipose tissue samples (approximately $100 \mathrm{mg}$ ) of German Holstein cows were treated for 90 min ex vivo with nicotinic acid $(2,8$, or $32 \mu M)$, nicotinamide $(2,8$, or $32 \mu M), \beta$-hydroxybutyrate $(0.2,1$, or $5 \mathrm{mM})$, or insulin $(12 \mathrm{mU} / \mathrm{L})$, with a concurrent lipolytic challenge provoked with $1 \mu M$ isoproterenol. Lipolytic and antilipolytic responses of the adipose tissues were assessed by measuring free glycerol and nonesterified fatty acid release. To identify molecular components of the investigated antilipolytic pathways, protein abundance of GPR109A and the extent of hormone-sensitive lipase (HSL) phosphorylation at serine residue 563 were detected by Western blotting. Treatment with nicotinic acid or $\beta$-hydroxybutyrate decreased the lipolytic response in adipose tissue explants and concurrently reduced the extent of HSL phosphorylation, but treatment with nicotinamide or insulin did not. Subcutaneous adipose tissue constitutively expressed more GPR109A protein, but no other depot-specific differences were observed. This study provides evidence that the GPR109A-mediated pathway is functionally existent in bovine adipose tissues, and confirms that HSL phosphorylation at serine residue 563 is also important in antilipolytic regulation
\end{abstract}

Received October 31, 2013.

Accepted February 24, 2014.

${ }^{1}$ Corresponding author: korinna.huber@tiho-hannover.de in vitro. This antilipolytic pathway may be involved in a balanced lipid mobilization in the dairy cow.

Key words: lipolysis, adipose tissue, hormone-sensitive lipase, GPR109A

\section{INTRODUCTION}

Cellular mechanisms to promote lipolysis have been studied in detail in subcutaneous adipose tissue of dairy cows, mainly focusing on activating prolipolytic pathways due to an increased energy need during early lactation (McNamara and Hillers, 1986a; McNamara, 1991; Koltes and Spurlock, 2011). In brief, the classical pathway of lipolysis to release endogenous energy from adipose stores can be stimulated by catecholamines through $\beta$-adrenergic receptors, leading to elevated intracellular cyclic AMP (cAMP) levels and activation of the protein kinase A (PKA) pathway. It was demonstrated in bovine adipocytes that this pathway is responsible for phosphorylation and thereby activation of proteins participating in triacylglycerol hydrolysis, including hormone-sensitive lipase (HSL; Garton et al., 1988; Carmen and Víctor, 2006). The phosphorylation site at serine residue 563 (Ser563) was shown to be important for bovine adipose tissue lipolysis (Elkins and Spurlock, 2009; Koltes and Spurlock, 2011; Locher et al., 2011).

During the transition period, this cellular lipolytic pathway becomes upregulated to provide endogenously stored energy needed for milk production and maintenance. However, excessive NEFA release from adipose depots is seen as a primary cause of production diseases, with the consequence of reduced animal welfare (Goff and Horst, 1997; Drackley et al., 2001). In this context, cellular mechanisms being able to limit lipolysis and thereby prohibiting excessive NEFA release are of special interest. Identifying such antilipolytic pathways and modulatory factors expressed in bovine adipose tissues as a fundamental physiological approach would contribute to improve dairy health management 
by helping to develop strategies to achieve balanced lipomobilization during the transition period.

Lipolysis could be counteracted by the G-proteincoupled receptor 109A (GPR109A)-mediated pathway, which has ligands such as nicotinic acid and BHBA. The antilipolytic effect of nicotinic acid was already demonstrated in rat adipose tissue (Carlson, 1963) and its cellular target, GPR109A (analogous to human HM74A and murine PUMA-G) has been identified as well (Lorenzen et al., 2001; Wise, 2003). The binding of nicotinic acid to this receptor was shown to be responsible for its antilipolytic action through inhibiting adenylyl cyclase and reducing intracellular levels of cAMP in murine adipocytes (Tunaru et al., 2003). In vivo trials demonstrated that feeding encapsulated nicotinic acid to Holstein cows in the transition period or i.v. infusing nicotinic acid to Holstein steers was followed by a decrease in the plasma NEFA level (Morey et al., 2011; Titgemeyer et al., 2011a). The receptor protein was shown to be present in bovine adipose tissues as well (Titgemeyer et al., 2011b). Nevertheless, the antilipolytic potential of the GPR109A-mediated pathway in bovine adipose tissue in vitro has not yet been investigated on a molecular level.

Insulin is a classical agent, considered to have antilipolytic effects by upregulating phosphodiesterase $3 \mathrm{~B}$ activity. The insulin receptor and other key components of the insulin signaling pathway are known to be present at least as transcripts in adipocytes of dairy cows (Sadri et al., 2010; Ji et al., 2012). Insulin infusion to dairy cows during a euglycemic-hyperinsulinemic clamp trial was followed by a decrease in plasma NEFA concentration, suggesting antilipolytic action of insulin (Kusenda et al., 2013). Nevertheless, it has not yet been confirmed that bovine adipose tissues respond with a reduced NEFA or glycerol release to an in vitro insulin treatment.

The hypothesis of the present study was that GPR109A and insulin receptor-mediated pathways provoke inhibition of adrenergic-induced lipolysis by diminishing HSL phosphorylation at Ser563 in different bovine adipose tissues. It was expected that depotspecific differences occur regarding the responsiveness of adipose tissues to antilipolytic agents.

The aim of the study was to identify causal relationships between plasma-derived antilipolytic factors and the cellular response of adipose tissues of dairy cows. Therefore, the antilipolytic effects of nicotinic acid, nicotinamide, BHBA, and insulin on isoproterenolstimulated lipolysis in isolated bovine subcutaneous (SCAT) and retroperitoneal adipose tissues (RPAT) were evaluated in vitro. Antilipolytic response was assessed by measuring adipose glycerol and NEFA release. To confirm the linkage between lipolytic flux and HSL phosphorylation at Ser563, semiquantitative Western blot analysis of this phosphoprotein was performed in the incubated adipose tissue samples.

\section{MATERIALS AND METHODS}

\section{Adipose Tissue Sampling}

This in vitro study was conducted on representative adipose tissue samples collected from the SCAT and the RPAT depot of 16 German Holstein cows. The animals were kept at the Institute of Animal Nutrition, Federal Research Institute for Animal Health (Friedrich-Loeffler-Institute, Braunschweig, Germany) in a freestall housing system and fed a grass silage-corn silage-based diet. Only clinically healthy, multiparous, lactating (early to mid-lactation) cows were selected for tissue sampling. However, in accordance with the main objective of the study, it was not our aim to reveal any correlations between the investigated in vitro tissue metabolism and specific physiologic conditions of the cows. Therefore, animal-related factors (e.g., parity, DIM, feed intake, milk yield, and BCS, among others) were not taken into consideration during the selection of the animals and the evaluation of the results.

Biopsy samples of SCAT and RPAT were surgically collected from 10 cows. Biopsy sampling was conducted under local anesthesia induced with $2 \%$ procaine (Procasel $2 \%$; Selectavet Dr. Otto Fischer GmbH., WeyarnHolzolling, Germany). Further SCAT and RPAT samples were collected from another 6 cows during the slaughtering process, immediately after the death of the animal. Cows were slaughtered at the institutional slaughterhouse. All samples were processed in tissue explant studies focusing on the metabolic response toward an in vitro treatment, gathering information at the level of adipose tissue as an organ.

Samples were collected from the SCAT depot at the tail head and from the RPAT depot below the lumbar vertebrae of each cow. After removal, tissue samples were trimmed of connective tissue and rinsed thoroughly in $37^{\circ} \mathrm{C}$ physiological saline solution to reduce blood contamination. Subsequently, samples were cut into equally sized and shaped pieces using a pair of fine surgical scissors and were immediately processed in an in vitro lipolysis assay.

\section{Lipolysis Assay}

In vitro lipolytic response was assessed according to McNamara and Hillers (1986b), with modifications described below. Triplicate samples of SCAT and RPAT tissue were incubated ex vivo in the presence of nicotinic acid $(\mathrm{n}=6)$, nicotinamide $(\mathrm{n}=6)$, BHBA ( 
$=6)$, or insulin $(\mathrm{n}=10)$ to stimulate the GPR109Amediated pathway and the insulin signaling pathway, respectively. Nicotinic acid, nicotinamide, and insulin treatments were applied on tissues collected via biopsy sampling, and BHBA treatment was applied on the samples collected after slaughter.

First, tissues were preincubated in Dulbecco's modified Eagle's medium (Life Technologies Corp., Paisley, UK) containing 2\% FA-free BSA (Sigma-Aldrich, St. Louis, MO) for $20 \mathrm{~min}$ at $37^{\circ} \mathrm{C}$ to diminish unspecific release of metabolites due to handling and cutting. Furthermore, soluble factors existing in the extracellular space in vivo were assumed to be removed from the tissues by this preincubation. Each sample (about 100 $\mathrm{mg}$ ) was then incubated separately in $1 \mathrm{~mL}$ of freshly prepared Dulbecco's modified Eagle's medium containing 2\% FA-free BSA (incubation medium) for $90 \mathrm{~min}$ at $37^{\circ} \mathrm{C}$ with gentle shaking. During this incubation, samples were challenged with pro- and antilipolytic stimuli, as they were processed in 1 of the 4 treatment groups (I, II, III, or IV) described below. In each treatment group, the incubation medium was supplemented with a $1 \mu M$ final concentration of the nonselective $\beta$-adrenoceptor agonist isoproterenol (Sigma-Aldrich) to promote lipolysis, and with increasing concentrations of 1 of the following antilipolytic agents: (I) nicotinic acid (Sigma-Aldrich), (II) nicotinamide (Sigma-Aldrich), (III) sodium D-BHBA (Sigma-Aldrich), or (IV) bovine insulin (Akron Biotechnology LLC, Boca Raton, FL). In detail, nicotinic acid and nicotinamide were applied at concentrations of 2,8 , and $32 \mu M$; BHBA was applied at concentrations of $0.2,1.0$, and $5.0 \mathrm{mM}$; and insulin was applied at a concentration of $12 \mathrm{mU} / \mathrm{L}$. As controls, 1 set with isoproterenol supplementation only and 1 set without any supplementation was incubated.

Following incubation, tissue samples were briefly drained, weighed, and afterward stored at $-80^{\circ} \mathrm{C}$ until Western blot analysis. Incubation media were stored at $-20^{\circ} \mathrm{C}$ until further biochemical analysis.

To assess lipolytic response of the incubated tissue samples, glycerol concentration (free glycerol reagent; Sigma-Aldrich) in the incubation media of treatment groups I to IV and NEFA concentration [NEFA-HR(2); Wako Chemicals GmbH., Neuss, Germany] in the incubation media of I, II, and IV were measured. Concentrations of glycerol and NEFA were corrected for wet weight ( $\mu \mathrm{mol}$ of metabolite/g of tissue per $90 \mathrm{~min}$ of incubation). Glycerol and NEFA release of samples without stimulation (basal lipolysis) was compared with the release of samples treated with isoproterenol (induced lipolysis) to assess prolipolytic responsiveness of tissue explants. Glycerol and NEFA release of samples treated with the combination of isoproterenol and 1 of the investigated antilipolytic agents were compared with the release of isoproterenol-treated samples and the difference was considered as the antilipolytic effect of the applied agent.

\section{Western Blot Analysis}

The technical replicates of the triplicate tissue incubation were pooled together and about $200 \mathrm{mg}$ of these samples were ground in $0.7-\mathrm{mL}$ lysis buffer $[50 \mathrm{mM}$ HEPES (Carl Roth GmbH, Karlsruhe, Germany), 4 $\mathrm{m} M$ ethylene glycol-bis(2-aminoethylether)- $N, N, N^{\prime}, N^{\prime}$ tetraacetic acid (Sigma-Aldrich), $10 \mathrm{~m} M$ EDTA (SigmaAldrich), 0.1\% Triton X-100 (Sigma-Aldrich), $100 \mathrm{mM}$ $\beta$-glycerol phosphate (Sigma-Aldrich), $15 \mathrm{~m} M$ sodium pyrophosphate (Sigma-Aldrich), $5 \mathrm{~m} M$ sodium orthovanadate (Sigma-Aldrich), $2.5 \mathrm{~m} M$ sodium fluoride (Sigma-Aldrich), protease inhibitor (cOmplete, Mini; Roche Diagnostics GmbH, Mannheim, Germany), and phosphatase inhibitor (PhosSTOP; Roche Diagnostics $\mathrm{GmbH})$ ] and incubated for $2 \mathrm{~h}$ at $4{ }^{\circ} \mathrm{C}$ with gentle shaking. Mixtures were subsequently homogenized using a 22 -gauge needle and finally centrifuged at $1,000 \times g$ for $10 \mathrm{~min}$ at $4^{\circ} \mathrm{C}$. Aliquots of the supernatants were stored at $-20^{\circ} \mathrm{C}$ until electrophoresis. Protein concentration in the supernatants was measured using Bradford reagent (Serva Electrophoresis GmbH, Heidelberg, Germany).

Protein extracts were diluted to $0.5 \mathrm{mg} / \mathrm{mL}$ in loading buffer $[50 \mathrm{~m} M$ Tris- $\mathrm{HCl}$ (Sigma-Aldrich), $10 \%$ glycerol (Sigma-Aldrich), 2\% SDS (Serva Electrophoresis $\mathrm{GmbH}$ ), 0.1\% bromophenol blue (Sigma-Aldrich), and $2 \%$ mercaptoethanol (Sigma-Aldrich); final concentrations] and heated at $95^{\circ} \mathrm{C}$ for $5 \mathrm{~min}$. Ten micrograms protein per lane were separated by SDS-PAGE on $8.1 \%$ gels and transferred to nitrocellulose membranes. Membranes were blocked in PBS solution containing $5 \%$ fat-free milk powder (Carl Roth $\mathrm{GmbH}$.) and $0.1 \%$ Tween 20 (Sigma-Aldrich) for $1 \mathrm{~h}$ at room temperature and then incubated with a rabbit anti-phospho-HSL antibody that detects endogenous levels of HSL protein only when phosphorylated at Ser563 (1:1,000 dilution; Cell Signaling Technology Inc., Danvers, MA), overnight at $4^{\circ} \mathrm{C}$. This antibody was used by Elkins and Spurlock (2009) and by Locher et al. (2011) to detect HSL phosphorylation in bovine adipose tissues. Membranes were incubated with a corresponding secondary antibody (anti-rabbit-HRP, 1:2,500 dilution; Cell Signaling Technology Inc.) for $1 \mathrm{~h}$ at room temperature. Immunodetection was performed by incubating the membranes with LumiGLO reagent (Cell Signaling Technology Inc.) and chemiluminescence was detected by a ChemiDoc XRS+ system (Bio-Rad Laboratories GmbH., München, Germany). Bands were quantified by densitometry using Image Lab 4.0 software (BioRad Laboratories GmbH.). 
Membranes containing samples of untreated (basal) incubation sets were additionally incubated with a goat anti-HM74 antibody (1:100 dilution; Santa Cruz Biotechnology Inc., Santa Cruz, CA) overnight at $4^{\circ} \mathrm{C}$ and afterward with an anti-goat-HRP secondary antibody (1:80,000 dilution; Sigma-Aldrich) for $1 \mathrm{~h}$ at room temperature. The anti-HM74 antibody was already successfully used by Titgemeyer et al. (2011b) to detect GPR109A protein abundance in bovine adipose tissues. Immunodetection was performed in this case by using SuperSignal West Dura substrate (Thermo Scientific, Rockford, IL). Detection of chemiluminescence and quantification of bands was carried out using the same method as described above.

\section{Statistical Analysis}

The arithmetic means of the technical replicates $(\mathrm{n}=$ 3) were used for data analysis. Hormone-sensitive lipase phosphorylation, glycerol release, and NEFA release of untreated (basal) and isoproterenol-treated (stimulated) incubation sets were compared using Student's $t$-test for each of the 4 treatment groups (nicotinic acid, nicotinamide, BHBA, and insulin) in SCAT and in RPAT. Within treatment groups, glycerol release, NEFA release, and HSL phosphorylation of isoproterenol-treated and antilipolytically treated incubation sets were analyzed using 2-way ANOVA for factor tissue (effect of different adipose depots), factor treatment (effect of increasing concentrations of the respective antilipolytic agent), and interactions. The Tukey posttest was performed for multiple comparisons between isoproterenol-treated and antilipolytically treated incubation sets (for SCAT and RPAT collectively where ANOVA revealed no tissue-specific differences). The GPR109A protein expression was compared between SCAT and RPAT using Student's t-test.

\section{RESULTS}

\section{Lipolysis Assay}

Glycerol Release. In each treatment group, isoproterenol-treated tissues released greater amounts of glycerol than untreated (basal) samples $(P<0.01$, data not shown). Samples treated simultaneously with isoproterenol and nicotinic acid at any concentration showed remarkably lower glycerol release compared with samples treated with isoproterenol only (treatment: $P<0.001$; tissue: NS; treatment $\times$ tissue: NS; posttest for each concentration of nicotinic acid compared with isoproterenol treatment: $P<0.001$; Figure 1A). The BHBA treatment caused decreased glycerol release as well, but only at the highest applied concentration (treatment: $P<0.001$; tissue: NS; treatment $\times$ tissue: $P=0.02$; posttest for $5.0 \mathrm{~m} M$ BHBA: $P<0.001$; Figure $2 \mathrm{~A}$ ). In contrast, the presence of nicotinamide or insulin did not alter the glycerol release induced by isoproterenol (data not shown). Glycerol release of SCAT and RPAT did not differ in any instance.

NEFA Release. Similar to glycerol release, NEFA release was also greater in isoproterenol-treated tissue samples than in untreated (basal) ones in each treatment group $(P<0.01$, data not shown). Treatment with nicotinic acid was again associated with a reduced lipolytic response: incubation sets containing both isoproterenol and nicotinic acid released significantly lower amounts of NEFA (treatment: $P<0.001$; tissue: NS; treatment $\times$ tissue: NS; posttest for each concentration of nicotinic acid: $P<0.001$; Figure 1B). Treatment with nicotinamide or insulin did not cause any significant change in NEFA release (data not shown). Nonesterified FA release of SCAT and RPAT did not differ in any instance. Lipolysis assays carried out with nicotinic acid, nicotinamide, and insulin showed that glycerol release on its own was a powerful indicator of changes in the lipolytic response and, for this reason, no NEFA release was measured in BHBA-stimulated incubation sets.

\section{Western Blot Analysis}

Extent of HSL Phosphorylation at Ser563. Hormone-sensitive lipase protein of isoproterenoltreated samples was phosphorylated to a greater extent compared with untreated (basal) ones in each treatment group $(P<0.05$, data not shown). Samples treated simultaneously with isoproterenol and nicotinic acid had significantly lower amounts of phosphorylated HSL protein than samples treated with isoproterenol only (treatment: $P<0.001$; tissue: NS; treatment $\times$ tissue: NS; posttest for each concentration of nicotinic acid: $P<0.001$; Figure $1 \mathrm{C}$ ). The BHBA treatment caused a decrease in HSL phosphorylation as well, but only at the highest applied concentration (treatment: $P$ $=0.01$; tissue: NS; treatment $\times$ tissue: NS; posttest for $5.0 \mathrm{~m} M$ BHBA: $P=0.007$; Figure $2 \mathrm{~B}$ ). Nicotinamide or insulin did not trigger any changes in the extent of HSL phosphorylation (data not shown). Hormone-sensitive lipase phosphorylation of SCAT and RPAT did not differ in any instance.

Expression of GPR109A. The GPR109A protein expression was greater in SCAT than in RPAT $(1,737$ \pm 468 vs. $654 \pm 128$ arbitrary units; mean \pm SEM; $P$ $=0.01)$.

\section{DISCUSSION}

The main finding of this fundamental research approach is that in bovine SCAT and RPAT, the 
A

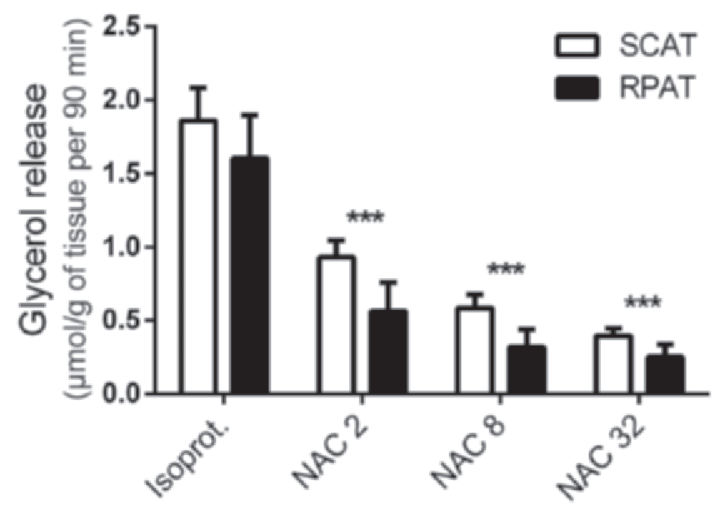

B

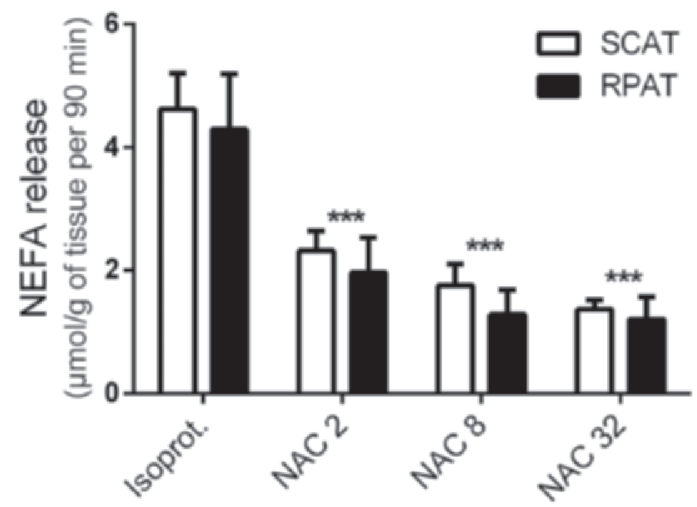

C

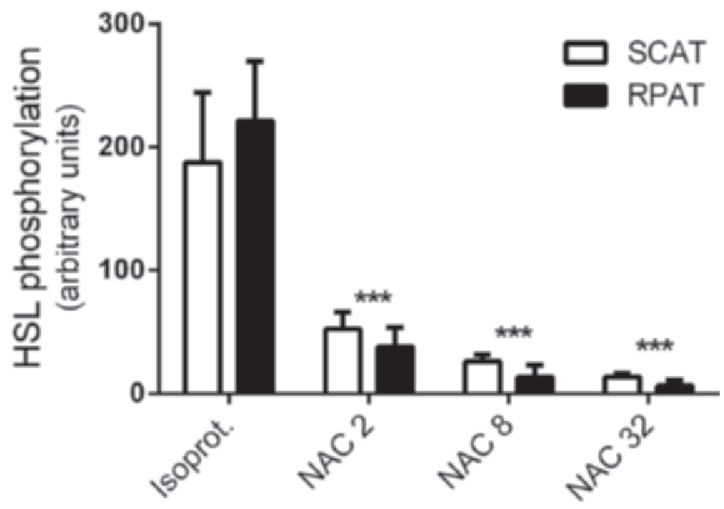

Figure 1. (A) Glycerol release, (B) NEFA release, and (C) extent of hormone-sensitive lipase (HSL) phosphorylation at serine residue 563 (Ser563) of subcutaneous (SCAT) and retroperitoneal adipose tissue (RPAT) biopsy samples of German Holstein cows. Figures show mean $( \pm \mathrm{SEM})$ values of samples treated with the combination of $1 \mu M$ isoproterenol and $0,2,8$, or $32 \mu M$ nicotinic acid in vitro [isoproterenol (Isoprot.), NAC 2, NAC 8, or NAC 32, respectively]. Asterisks above bars indicate significant differences between treatment group without any nicotinic acid (Isoprot.) and treatment groups with nicotinic acid (NAC 2, NAC 8, and NAC 32), calculated for both tissues together using the Tukey posttest. $* * * P<0.001$.
GPR109A antilipolytic pathway, already described in other mammal species, does exist in a functioning form; and the stimulation of this pathway with physiological agonists under in vitro conditions resulted in a decreased lipolytic response of adipose tissues, which was caused by a reduced phosphorylation of Ser563 in the HSL protein.

\section{Lipolytic Response}

This study confirmed that Ser563 in bovine HSL protein is an important phosphorylation site, inducing alterations in NEFA and glycerol release and thus possessing a central regulatory function in lipolysis. Isoproterenol, as a well-known activator of the $\beta$-adrenergic pathway, caused increased lipolytic activity, as already described in previous studies (McNamara et al., 1992; Khan et al., 2013). The mechanism of this action incorporates the $\beta$-adrenoceptor-cAMP-PKA-HSL axis, leading to the phosphorylation of HSL (Holm et al., 2000; Sumner and McNamara, 2007).

Serine residues as potential phosphorylation sites in bovine HSL protein were already identified in the late 1980s (Garton et al., 1988, 1989; Garton and Yeaman, 1990). In addition, HSL phosphorylation at Ser563 was observed to be associated with the peripartal variation in energy metabolism in previous studies (Elkins and Spurlock, 2009; Koltes and Spurlock, 2011; Locher et al., 2011). The term Ser563 is used throughout the text to stay consistent with the literature mentioned above; however, this numbering refers to the rat HSL protein sequence and it corresponds to Ser552 in bovine HSL. Phosphorylation of Ser660 was also shown to increase during early lactation (Locher et al., 2011), but no further phosphorylation sites or the exact physiological function of the known phosphorylation sites have been studied in bovine adipose tissues in detail. Concurrent alterations of HSL phosphorylation and lipolytic flux in bovine SCAT and RPAT have not been previously studied either.

Results of the present study confirmed the hypothesized causal relationship between the extent of HSL phosphorylation and NEFA release in bovine adipose tissues, directly linking this regulatory mechanism at protein level to adipose tissue metabolic activity. Nevertheless, this finding explained the role of phosphorylating HSL at Ser563 only. Just as in the case of humans and rodents, HSL protein of cattle also contains more than 1 phosphorylation site. Analyzing the human and rat HSL revealed that phosphorylation sites have different enzyme activity-controlling properties, with possible interactions between these sites, emphasizing the complexity of regulating HSL activity through multiple phosphorylation sites (Anthonsen et al., 1998; Krintel 
et al., 2009). However, in dairy cows, the physiological role of these different phosphorylation sites of HSL is still not clearly elucidated. Further research is necessary to fully understand the regulation of lipolysis in bovine adipose tissues.

\section{Antilipolytic Response}

In this study, the causal role of GPR109A and insulin receptor-mediated antilipolytic pathways in the lipolytic fine-tuning machinery of bovine adipose tissues was examined. To stimulate these pathways, ex vivo treatments of tissue samples with potentially antilipolytic agents were performed using concentrations that reflect physiological plasma concentrations of dairy cows (e.g., concentrations of nicotinic acid and nicotinamide were chosen according to plasma concentrations after niacin feeding measured by Campbell et al. (1994), Niehoff et al. (2009), and Hüther et al. (L. Hüther, U. Meyer, and S. Kersten, Institute of Animal Nutrition, Friedrich-Loeffler-Institute, Braunschweig, Germany; unpublished data, 2011). However, it was not the primary aim to extrapolate the results of this basic research approach to the in vivo conditions and systemic regulation of metabolism in dairy cows fed with a niacin-supplemented diet.

In this study, both SCAT and RPAT were examined, because previous research provides evidence that metabolic activity differs between subcutaneous and visceral depots. A greater lipolytic potential is suggested for RPAT, as it was shown to express more HSL and have a greater extent of HSL phosphorylation in times of intensive lipomobilization than SCAT (Locher et al., 2011). The GPR109A was also shown to differ in the level of its protein expression between adipose tissues in Holstein steers (Titgemeyer et al., 2011b). In the present study using German Holstein cows, GPR109A expression also varied between SCAT and RPAT. However, different levels of receptor protein abundance did not result in different antilipolytic responsiveness. In spite of a 3-fold greater receptor protein expression in SCAT, the inhibiting effect of nicotinic acid and BHBA on glycerol and NEFA release and HSL phosphorylation was not enhanced compared with RPAT. This may be explained by adjustments through constitutive counteracting pathways or differences in receptor-ligand affinity.

The GPR109A ligands nicotinic acid, nicotinamide, and BHBA showed different levels of effectiveness in inducing antilipolysis in vitro. Nicotinic acid decreased HSL phosphorylation at Ser563 and consequently reduced the lipolytic response. This indicates that the GPR109A-mediated pathway described in murine and humane adipocytes (Tunaru et al., 2003) is present in
A

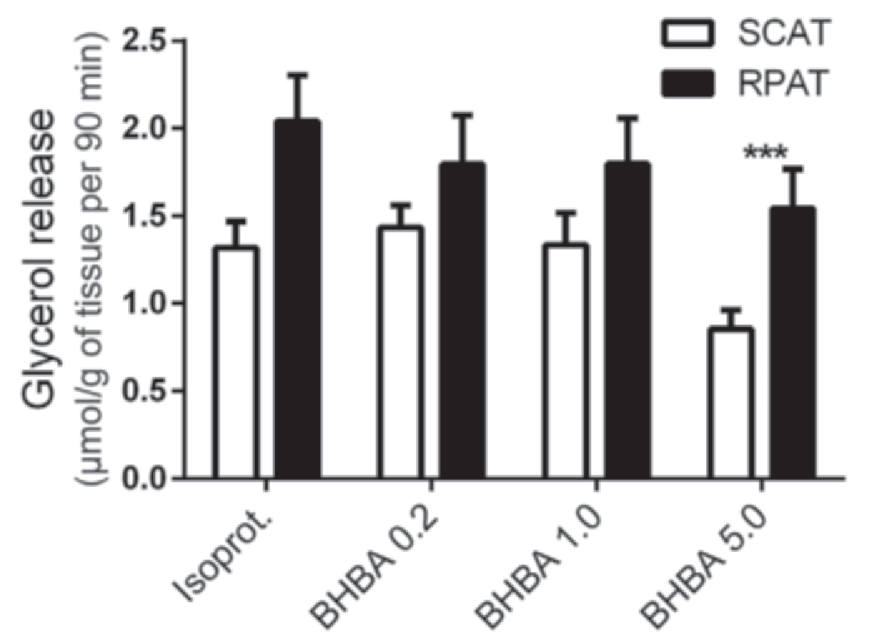

B

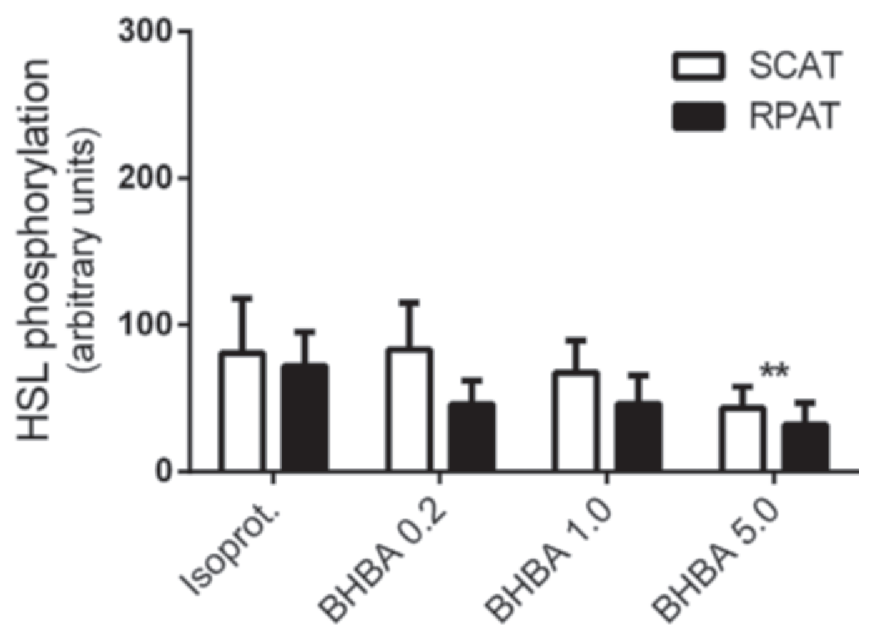

Figure 2. (A) Glycerol release and (B) extent of hormone-sensitive lipase (HSL) phosphorylation at serine residue 563 (Ser563) of subcutaneous (SCAT) and retroperitoneal adipose tissue (RPAT) samples of German Holstein cows. Figures show mean $( \pm$ SEM) values of samples treated with the combination of $1 \mu M$ isoproterenol and $0,0.2$, 1.0, or $5.0 \mathrm{~m} M \mathrm{BHBA}$ in vitro [isoproterenol (Isoprot.), BHBA 0.2, BHBA 1.0, or BHBA 5.0, respectively]. Asterisks above bars indicate significant differences between treatment group without any BHBA (Isoprot.) and treatment groups with BHBA (BHBA 0.2, BHBA 1.0, and BHBA 5.0), calculated for both tissues together using the Tukey posttest. $* * P<0.01$; *** $P<0.001$.

dairy cow adipose tissues as well and is an efficient way to downregulate lipolysis in vitro. On the other hand, this finding confirmed that Ser563 in bovine HSL protein is a phosphorylation site that is also responsive to antilipolytic stimulation, being a target to downregulate adipose tissue NEFA release. 
In the context of lipomobilization in the dairy cow, this in vitro finding marks a potential control point to restrict NEFA release from adipose depots in a physiological way via the GPR109A-mediated pathway. Supporting the plasma NEFA-reducing effect of in vivo nicotinic acid treatment demonstrated by Morey et al. (2011) and Titgemeyer et al. (2011a), the present in vitro results suggest that an enhanced plasma concentration of nicotinic acid could cause a restricted level of HSL phosphorylation, possibly preventing excessive rates of lipolysis. The physiological relevance of this molecular mechanism should be confirmed in further in vivo studies by administering nicotinic acid to transition cows and subsequently analyzing cellular markers of lipolysis, such as phosphorylated HSL and perilipin.

Although nicotinamide does not differ very much in its biochemical properties from nicotinic acid, results of the present study showed that nicotinamide was not capable of suppressing lipolytic activity in isolated bovine adipose tissues. Reports regarding the antilipolytic effects of nicotinamide are somewhat inconsistent. In a feeding trial, nicotinamide supplementation of lactating dairy cows was associated with decreased plasma NEFA and BHBA concentrations, indicating reduced lipomobilization (Jaster and Ward, 1990). On the other hand, studies investigating receptor binding revealed that nicotinamide was inactive on GPR109A (Lorenzen et al., 2001; Wise, 2003). In rat epididymal adipose tissue explants, comparing antilipolytic effects of nicotinic acid and nicotinamide also demonstrated that nicotinic acid inhibited catecholamine-induced lipolysis, but nicotinamide did not (Carlson, 1963). To sum up, these observations suggest that, unlike nicotinic acid, nicotinamide cannot exert any inhibiting effect on catecholamine-induced lipolysis because it cannot activate GPR109A. Nonetheless, this has to be confirmed by investigating receptor-ligand interactions.

Only the highest concentration of BHBA $(5.0 \mathrm{mM})$ caused significantly lower glycerol release and HSL phosphorylation. A study in mouse adipocytes found that BHBA at a concentration of 2 and $20 \mathrm{mM}$, but not at $0.2 \mathrm{mM}$, reduced isoproterenol-induced NEFA release (Taggart et al., 2005). In noradrenaline-stimulated bovine SCAT, a $10 \mathrm{~m} M$ concentration of BHBA (Metz and van den Bergh, 1972) and $5 \mathrm{~m} M$ concentration of BHBA (Rukkwamsuk et al., 1998) was also shown to decrease NEFA or glycerol release in vitro.

Treatment concentrations of BHBA were chosen to reflect plasma concentrations of lactating dairy cows. As this might vary depending on the ketone body metabolism, the 3 applied concentrations can be assigned to plasma BHBA concentrations of cows being in different metabolic states $(0.2 \mathrm{mM}=$ healthy, $1.0 \mathrm{mM}$ $=$ subclinical ketosis, and $5.0 \mathrm{~m} M=$ clinical ketosis).
Accordingly, data show that a physiological concentration of BHBA was not able to reduce lipolysis, whereas a pathophysiologically high concentration could counteract isoproterenol-stimulated lipolysis. Nevertheless, this finding is limited to in vitro conditions at this point. Without further in vivo studies, it cannot be assessed if high plasma BHBA levels of cows suffering from ketosis can inhibit intensive lipolysis in adipose tissues. The GPR109A-mediated antilipolytic pathway could already be induced with $0.002 \mathrm{mM}$ nicotinic acid, whereas a 2,500-times greater concentration ( $5 \mathrm{mM}$ BHBA) was needed to evoke any effect. Although both substances act as agonists of the human HM74A and the mouse PUMA-G receptor (both analogous to the bovine GPR109A), shown by a cell culture study, it was revealed that nicotinic acid is about 8,000-times more active on these receptors than BHBA (Taggart et al., 2005).

Besides the GPR109A-mediated regulation of antilipolysis, insulin is considered to be the classical inhibitor of lipolysis by promoting activity of phosphodiesterase 3B and thereby reducing intracellular cAMP levels, resulting in decreased PKA activity and decreased HSL phosphorylation. In the current study, insulin was applied at a concentration $(12 \mathrm{mU} / \mathrm{L})$ reflecting a physiological plasma level in dairy cows (Vasilatos and Wangsness, 1981; Rukkwamsuk et al., 1998; Kusenda et al., 2013). Nevertheless, it was found that adipose tissue explants treated with $12 \mathrm{mU}$ of bovine insulin/L did not decrease their lipolytic response. It is still unknown if insulin was not able to exert any antilipolytic effects under the applied technical conditions (i.e., at this physiological concentration, in combination with 1 $\mu M$ isoproterenol) or if reduced insulin responsiveness of the tissue caused this lack of effect. It was demonstrated in in vitro-treated rat adipocytes that excessively upregulated PKA due to high concentrations of isoproterenol attenuated the antilipolytic effects of insulin (Londos et al., 1985). On the other hand, reduced systemic insulin sensitivity is a known phenomenon during early lactation in dairy cows (De Koster and Opsomer, 2013); however, the relative contribution of adipose tissues to that was not evaluated so far.

In view of a broader scope of control of lipolysis, the present study provides evidence of the existence and functionality of the GPR109A-mediated pathway as a novel mechanism in cows to downregulate lipolysis in subcutaneous and visceral adipose tissues. Because of the critical effect of lipolysis on metabolic health, corresponding mechanisms in transition cows were heavily studied and many sources of regulation have been identified during the last decades (see Yang and Baldwin, 1973; McNamara and Hillers, 1986b; Drackley, 1999; Sumner and McNamara, 2007; Khan et al., 2013). It 
was shown that upregulation of lipolysis in times of negative energy balance involves HSL phosphorylation as a key molecular target (Elkins and Spurlock, 2009; Koltes and Spurlock, 2011; Locher et al., 2011) and that this activation of lipolysis stays under the control of the sympathetic nervous system and endocrine factors, primarily under the influence of an enhanced adrenergic effect on $\beta$-receptors (Smith and McNamara, 1989; Sumner and McNamara, 2007). In previous research approaches, several cellular mechanisms were found to have antilipolytic effects in bovine adipose tissue, including $\alpha_{2}$-adrenergic receptor signaling (Smith and McNamara, 1989), AMP-activated protein kinase signaling (Garton et al., 1989), and $\mathrm{A}_{1}$-adenosine receptor signaling (Houseknecht et al., 1995). Nonetheless, these antilipolytic pathways are difficult to influence by exogenous factors such as dietary supplements. This underlines the relevance of the GPR109A-mediated pathway, as this might serve as a dietary accessible control point (e.g., by nicotinic acid supplementation) to restrict excessive lipolysis and contribute to balanced lipid metabolism in periparturient dairy cows. In fact, dietary niacin supplementation is not new to dairy nutrition, as previous in vivo studies found reduced plasma NEFA concentrations after nicotinic acid administration (for a review, see Niehoff et al., 2009). Nevertheless, plasma NEFA concentrations are always determined by multicausal effects modulating NEFA release and utilization. In this respect, our tissue explant study demonstrating the antilipolytic effect of nicotinic acid via the GPR109A-mediated pathway confirms and complements the previous in vivo findings, as tissue explants generally allow the study of monocausal effects (i.e., in this case, the alteration in NEFA release by the adipose tissue after in vitro stimulating a cellular pathway).

To summarize, our in vitro results indicate that dietary supplementation of nicotinic acid but not of nicotinamide might be beneficial for transition cows by supporting more balanced lipomobilization. However, further studies are required to determine if dietary supplemented nicotinic acid is able to downregulate the adipose cellular lipolytic pathway in vivo and to evaluate the quantitative contribution of plasma nicotinic acid levels to overall lipolytic control.

\section{CONCLUSIONS}

Treating dairy cow adipose tissue samples in vitro with physiological plasma concentrations of nicotinic acid and pathophysiologically high concentrations of BHBA caused reduced phosphorylation of HSL at Ser563 and decreased lipolysis. These findings indicate that stimulating GPR109A triggers a potent pathway to downregulate lipolysis in vitro in adipose tissues of dairy cows and that phosphorylation of HSL at Ser563 has a regulatory role in this cellular mechanism.

\section{ACKNOWLEDGMENTS}

The financial support of the German Research Foundation (DFG, Bonn, Germany) and the German Academic Exchange Service (DAAD, Bonn, Germany) as well as the valuable technical assistance of Kathrin Hansen and Susanne Hoppe (both of Department of Physiology, University of Veterinary Medicine, Hannover, Germany) is gratefully acknowledged.

\section{REFERENCES}

Anthonsen, M. W., L. Rönnstrand, C. Wernstedt, E. Degerman, and C. Holm. 1998. Identification of novel phosphorylation sites in hormone-sensitive lipase that are phosphorylated in response to isoproterenol and govern activation properties in vitro. J. Biol. Chem. 273:215-221. http://dx.doi.org/10.1074/jbc.273.1.215.

Campbell, J. M., M. R. Murphy, R. A. Christensen, and T. R. Overton. 1994. Kinetics of niacin supplements in lactating dairy cows. J. Dairy Sci. 77:566-575.

Carlson, L. A. 1963. Studies on the effect of nicotinic acid on catecholamine stimulated lipolysis in adipose tissue in vitro. Acta Med. Scand. 173:719-722.

Carmen, G.-Y., and S.-M. Víctor. 2006. Signalling mechanisms regulating lipolysis. Cell. Signal. 18:401-408. http://dx.doi. org/10.1016/j.cellsig.2005.08.009.

De Koster, J. D., and G. Opsomer. 2013. Insulin resistance in dairy cows. Vet. Clin. North Am. Food Anim. Pract. 29:299-322. http://dx.doi.org/10.1016/j.cvfa.2013.04.002.

Drackley, J. K. 1999. Biology of dairy cows during the transition period: The final frontier? J. Dairy Sci. 82:2259-2273. http://dx.doi. org/10.3168/jds.S0022-0302(99)75474-3.

Drackley, J. K., T. R. Overton, and G. N. Douglas. 2001. Adaptations of glucose and long-chain fatty acid metabolism in liver of dairy cows during the periparturient period. J. Dairy Sci. 84(Suppl.):E100 E112. http://dx.doi.org/10.3168/jds.S0022-0302(01)70204-4.

Elkins, D. A., and D. M. Spurlock. 2009. Phosphorylation of perilipin is associated with indicators of lipolysis in Holstein cows. Horm. Metab. Res. 41:736-740. http://dx.doi. org/10.1055/s-0029-1225359.

Garton, A. J., D. G. Campbell, D. Carling, D. G. Hardie, R. J. Colbran, and S. J. Yeaman. 1989. Phosphorylation of bovine hormonesensitive lipase by the AMP-activated protein kinase. A possible antilipolytic mechanism. Eur. J. Biochem. 179:249-254.

Garton, A. J., D. G. Campbell, P. Cohen, and S. J. Yeaman. 1988. Primary structure of the site on bovine hormone-sensitive lipase phosphorylated by cyclic AMP-dependent protein kinase. FEBS Lett. 229:68-72.

Garton, A. J., and S. J. Yeaman. 1990. Identification and role of the basal phosphorylation site on hormone-sensitive lipase. Eur. J. Biochem. 191:245-250.

Goff, J. P., and R. L. Horst. 1997. Physiological changes at parturition and their relationship to metabolic disorders. J. Dairy Sci. 80:1260 1268. http://dx.doi.org/10.3168/jds.S0022-0302(97)76055-7.

Holm, C., T. Østerlund, H. Laurell, and J. A. Contreras. 2000. Molecular mechanisms regulating hormone-sensitive lipase and lipolysis. Annu. Rev. Nutr. 20:365-393.

Houseknecht, K. L., D. E. Bauman, G. B. Carey, and H. J. Mersmann. 1995. Effect of bovine somatotropin and food deprivation on $\beta$-adrenergic and $A_{1}$ adenosine receptor binding in adipose tissue of lactating cows. Domest. Anim. Endocrinol. 12:325-336. http://dx.doi.org/10.1016/0739-7240(95)00029-E. 
Jaster, E. H., and N. E. Ward. 1990. Supplemental nicotinic acid or nicotinamide for lactating dairy cows. J. Dairy Sci. 73:2880-2887.

Ji, P., J. S. Osorio, J. K. Drackley, and J. J. Loor. 2012. Overfeeding a moderate energy diet prepartum does not impair bovine subcutaneous adipose tissue insulin signal transduction and induces marked changes in peripartal gene network expression. J. Dairy Sci. 95:4333-4351. http://dx.doi.org/10.3168/jds.2011-5079.

Khan, M. J., A. Hosseini, S. Burrell, S. M. Rocco, J. P. McNamara, and J. J. Loor. 2013. Change in subcutaneous adipose tissue metabolism and gene network expression during the transition period in dairy cows, including differences due to sire genetic merit. J. Dairy Sci. 96:2171-2182. http://dx.doi.org/10.3168/jds.20125794 .

Koltes, D. A., and D. M. Spurlock. 2011. Coordination of lipid dropletassociated proteins during the transition period of Holstein dairy cows. J. Dairy Sci. 94:1839-1848. http://dx.doi.org/10.3168/ jds.2010-3769.

Krintel, C., M. Mörgelin, D. T. Logan, and C. Holm. 2009. Phosphorylation of hormone-sensitive lipase by protein kinase A in vitro promotes an increase in its hydrophobic surface area. FEBS J. 276:4752-4762. http://dx.doi.org/10.1111/j.17424658.2009.07172.x.

Kusenda, M., M. Kaske, M. Piechotta, L. Locher, A. Starke, K. Huber, and J. Rehage. 2013. Effects of dexamethasone-21-isonicotinate on peripheral insulin action in dairy cows 5 days after surgical correction of abomasal displacement. J. Vet. Intern. Med. 27:200-206. http://dx.doi.org/10.1111/jvim.12010.

Locher, L. F., N. Meyer, E.-M. Weber, J. Rehage, U. Meyer, S. Dänicke, and K. Huber. 2011. Hormone-sensitive lipase protein expression and extent of phosphorylation in subcutaneous and retroperitoneal adipose tissues in the periparturient dairy cow. J. Dairy Sci. 94:4514-4523. http://dx.doi.org/10.3168/jds.2011-4145.

Londos, C., R. C. Honnor, and G. S. Dhillon. 1985. cAMP-dependent protein kinase and lipolysis in rat adipocytes. III. Multiple modes of insulin regulation of lipolysis and regulation of insulin responses by adenylate cyclase regulators. J. Biol. Chem. 260:15139-15145.

Lorenzen, A., C. Stannek, H. Lang, V. Andrianov, I. Kalvinsh, and U. Schwabe. 2001. Characterization of a G protein-coupled receptor for nicotinic acid. Mol. Pharmacol. 59:349-357.

McNamara, J. P. 1991. Regulation of adipose tissue metabolism in support of lactation. J. Dairy Sci. 74:706-719.

McNamara, J. P., B. Becker-Khaleel, and K. L. Parmley. 1992. Quantitative relationships between cyclic adenosine-3', $5^{\prime}$-monophosphate and lipolysis in adipose tissue during the peripartum period. J. Dairy Sci. 75:1901-1913.

McNamara, J. P., and J. K. Hillers. 1986a. Regulation of bovine adipose tissue metabolism during lactation. 2. Lipolysis response to milk production and energy intake. J. Dairy Sci. 69:3042-3050.

McNamara, J. P., and J. K. Hillers. 1986b. Adaptations in lipid metabolism of bovine adipose tissue in lactogenesis and lactation. J. Lipid Res. 27:150-157.

Metz, S. H. M., and S. G. van den Bergh. 1972. Effects of volatile fatty acids, ketone bodies, glucose, and insulin on lipolysis in bovine adipose tissue. FEBS Lett. 21:203-206.
Morey, S. D., L. K. Mamedova, D. E. Anderson, C. K. Armendariz, E. C. Titgemeyer, and B. J. Bradford. 2011. Effects of encapsulated niacin on metabolism and production of periparturient dairy cows. J. Dairy Sci. 94:5090-5104. http://dx.doi.org/10.3168/jds.20114304.

Niehoff, I.-D., L. Hüther, and P. Lebzien. 2009. Niacin for dairy cattle: A review. Br. J. Nutr. 101:5-19. http://dx.doi.org/10.1017/ S0007114508043377.

Rukkwamsuk, T., T. Wensing, and M. J. Geelen. 1998. Effect of overfeeding during the dry period on regulation of adipose tissue metabolism in dairy cows during the periparturient period. J. Dairy Sci. 81:2904-2911

Sadri, H., R. M. Bruckmaier, H. R. Rahmani, G. R. Ghorbani, I Morel, and H. A. van Dorland. 2010. Gene expression of tumour necrosis factor and insulin signalling-related factors in subcutaneous adipose tissue during the dry period and in early lactation in dairy cows. J. Anim. Physiol. Anim. Nutr. (Berl.) 94:e194-e202. http://dx.doi.org/10.1111/j.1439-0396.2010.01005.x.

Smith, D. J., and J. P. McNamara. 1989. Lipolytic response of bovine adipose tissue to alpha and beta adrenergic agents 30 days preand 120 days postpartum. Gen. Pharmacol. 20:369-374

Sumner, J. M., and J. P. McNamara. 2007. Expression of lipolytic genes in the adipose tissue of pregnant and lactating Holstein dairy cattle. J. Dairy Sci. 90:5237-5246. http://dx.doi.org/10.3168/ jds.2007-0307.

Taggart, A. K. P., J. Kero, X. Gan, T.-Q. Cai, K. Cheng, M. Ippolito, N. Ren, R. Kaplan, K. Wu, T.-J. Wu, L. Jin, C. Liaw, R. Chen, J. Richman, D. Connolly, S. Offermanns, S. D. Wright, and M. G. Waters. 2005. (D)- $\beta$-Hydroxybutyrate inhibits adipocyte lipolysis via the nicotinic acid receptor PUMA-G. J. Biol. Chem. 280:26649-26652. http://dx.doi.org/10.1074/jbc.C500213200.

Titgemeyer, E., K. Spivey, L. Mamedova, and B. Bradford. 2011a. Effects of pharmacological amounts of nicotinic acid on lipolysis and feed intake in cattle. Int. J. Dairy Sci. 6:134-141.

Titgemeyer, E. C., L. K. Mamedova, K. S. Spivey, J. K. Farney, and B. J. Bradford. 2011b. An unusual distribution of the niacin receptor in cattle. J. Dairy Sci. 94:4962-4967. http://dx.doi.org/10.3168/ jds.2011-4193.

Tunaru, S., J. Kero, A. Schaub, C. Wufka, A. Blaukat, K. Pfeffer, and S. Offermanns. 2003. PUMA-G and HM74 are receptors for nicotinic acid and mediate its anti-lipolytic effect. Nat. Med. 9:352355. http://dx.doi.org/10.1038/nm824.

Vasilatos, R., and P. J. Wangsness. 1981. Diurnal variations in plasma insulin and growth hormone associated with two stages of lactation in high producing dairy cows. Endocrinology 108:300-304 http://dx.doi.org/10.1210/endo-108-1-300.

Wise, A. 2003. Molecular identification of high and low affinity receptors for nicotinic acid. J. Biol. Chem. 278:9869-9874. http:// dx.doi.org/10.1074/jbc.M210695200.

Yang, Y. T., and R. L. Baldwin. 1973. Lipolysis in isolated cow adipose cells. J. Dairy Sci. 56:366-374. 